\title{
Ensino remoto em tempos de pandemia: a experiência da Pontifícia Universidade Católica de São Paulo (PUC-SP)
}

\section{Remote Education in times of pandemic: the experience of the Pontifícia Universidade Católica de São Paulo (PUC-SP)}

Julia Brum de Mello ${ }^{1}$ (D), Luiz Ferraz Sampaio Neto ${ }^{2}$ (D), Alexandra Fogli Serpa Geraldini ${ }^{3}$ (D), Mário Luís Ribeiro Cesaretti ${ }^{4}$ (D)

\begin{abstract}
RESUMO:
A Pontifícia Universidade Católica de São Paulo é uma universidade comunitária. Em março de 2020, o distanciamento/isolamento social ocasionado pela pandemia da SARS-CoV-2 impôs diversos desafios a serem enfrentados, relacionados à migração do ensino presencial para o ensino remoto/ capacitação tecnológica (e pedagógica) do corpo docente, suporte aos estudantes, capacitação tecnológica do corpo funcional e adequação da infraestrutura de tecnologia da informação. Neste trabalho trataremos da capacitação docente. Embora não existisse uma estrutura de desenvolvimento docente institucionalizada, um grupo de docentes envolvidos nas diversas capacitações que vinham sendo promovidas desde 2017 pela instituição, por iniciativa da Pró-Reitoria de Graduação, foi responsável pela capacitação do conjunto de docentes da Universidade para uso das plataformas institucionais. Também foram criados treinamentos individuais para atender às necessidades dos docentes. Superada a primeira fase de familiarização com as plataformas, a etapa seguinte foi suscitar, no corpo docente, a necessidade de qualificação das atividades remotas, por meio do uso de metodologias inovadoras de ensino. A necessidade de manutenção do ensino remoto levou à ampliação do grupo de docentes responsáveis pelo apoio às atividades remotas. Mais ainda, monitores pós-graduandos (mestrandos e doutorandos) dos diferentes cursos da universidade foram selecionados para auxiliar os docentes, de forma individualizada, para que fizessem o uso apropriado de estratégias de ensino e as plataformas tecnológicas. No curso de Medicina da PUC-SP, que tem em seu cerne o uso de estratégias ativas de ensino e aprendizagem, com exceção de parte das atividades práticas, todas foram realizadas remotamente. $\mathrm{A}$ adaptação das tutorias da aprendizagem baseada em problemas foi satisfatória. Um dos aprendizados mais significativos foi o trabalho colaborativo docente para a realização de avaliações somativas.
\end{abstract}

Palavras-Chave: Educação a Distância, Capacitação de Professores, Estudantes de Medicina, Aprendizagem Baseada em Problemas, Covid-19.

\footnotetext{
ABSTRACT:

The Pontifícia Universidade Católica de São Paulo (PUC-SP) is a community university. In March 2020, the social distancing caused by the SARS-CoV-2 pandemic imposed several challenges to be faced related to the migration from classroom teaching to remote teaching: technological (and pedagogical) training of the teaching staff, support for students, training of the staff and the adequacy of the Information technology infrastructure. In this work, we will deal with faculty development. Although there was no institutionalized faculty development structure, a group of teachers involved in the various training courses promoted since 2017 by the institution, under the Deanery of Undergraduate coordination, was responsible for training to help teachers to use the institutional platforms. Individual training was also proposed to meet specific needs. Following the first bare step of familiarization with the platforms, the next phase was to raise the need for qualification of remote activities in the teaching staff through innovative teaching methodologies. Maintaining remote education led to the expansion of the group of teachers re-

Médica, Mestranda do Programa de Educação para as Profissões da Saúde da Faculdade de Ciências Médicas e da Saúde da Pontifícia Universidade Católica de São Paulo

2 Médico, Professor titular de Ginecologia da Pontifícia Universidade Católica de São Paulo. Diretor da Faculdade de Ciências Médicas e da Saúde da Pontifícia Universidade Católica de São Paulo

3 Doutora, Pró-reitora de Graduação da Pontifícia Universidade Católica de São Paulo

4 Doutor, Assessor no Núcleo Assessor de Tecnologias Educacionais e Docente do Departamento de Clínica da Faculdade de Ciências Médicas e da Saúde, Pontifícia Universidade Católica de São Paulo
} 
sponsible for supporting remote activities. Furthermore, post-graduate (masters and doctoral students) acted as monitors from the different courses of the university. They were selected to assist teachers individually to make the appropriate use of teaching strategies and technological platforms. In the PUC-SP undergraduate medical course, which has at its core the use of active teaching and learning strategies, except for part of the practical activities, all were carried out remotely. The adaptation of the problem-based learning tutorials was satisfactory. One of the most significant apprenticeships was the collaborative teaching work for carrying out summative assessments.

KEY WORDS: Distance learning, Faculty development, Medicine undergraduate student, Problem based learning, Covid-19.

\section{MENSAGENS PRINCIPAIS:}

1. Na PUC-SP, apesar das dificuldades do corpo docente para o uso das ferramentas remotas, houve restabelecimento das atividades acadêmicas em aproximadamente dez dias após a interrupção das atividades acadêmicas presenciais.

2. A universidade já possuía cultura de capacitação docente e os professores envolvidos neste processo compuseram um grupo multiprofissional que tornou possível o início das atividades remotas.

3. O ensino remoto necessita de qualificação para a promoção do aprendizado significativo do estudante. Assim defendemos o uso de metodologias ativas de ensino e aprendizagem, bem como também a colaboração e interação dos estudantes.

4. A Faculdade de Ciências Médicas e da Saúde obteve resultados satisfatórios com o uso da Aprendizagem Baseada em Problemas no ensino remoto.

5. A necessidade de reinventar a forma de avaliar criou uma situação inédita de colaboração entre os docentes para a realização da avaliação somativa mais qualificada.

\section{INTRODUÇÃO}

A Pontifícia Universidade Católica de São Paulo (PUC-SP) é uma universidade privada, comunitária, sem fins lucrativos, vinculada à Ar- quidiocese da cidade de São Paulo e mantida pela Fundação São Paulo. Aos 75 anos de existência conta com aproximadamente dezoito mil estudantes matriculados em diferentes cursos de graduação, nos programas de pós-graduação stricto sensu, lato sensu e de extensão universitária. Atualmente existem aproximadamente 1.100 docentes contratados pela Universidade. Os cursos estão distribuídos em cinco campi, sendo quatro na cidade de São Paulo (Perdizes, Marquês de Paranaguá, Santana e Ipiranga) e um no município de Sorocaba. O campus sede - Perdizes- apresenta a maior concentração de cursos, distribuídos nas áreas de ciências humanas, sociais, educação, comunicação e da saúde. A Faculdade de Teologia ocupa os campi de Santana e Ipiranga, os cursos da área de exatas funcionam no campus Marquês de Paranaguá e o campus do município de Sorocaba é o local dos cursos de medicina e enfermagem. É importante destacar que o compromisso com a sociedade é uma característica fundante da PUC-SP, instituição que desempenha, desde sua criação, um papel protagonista na missão de transformar a sociedade, levando-a a ocupar uma posição de destaque na história deste país.

\section{A PUC-SP NA PANDEMIA E A TRAN- SIÇÃO PARA O ENSINO REMOTO: OS DESAFIOS INSTITUCIONAIS}

Em 17 de março de 2020, com o avanço da pandemia do SARS-CoV-2, considerando as determinações e recomendações das autoridades governamentais e de saúde do Estado de São Paulo, a PUC-SP suspende suas atividades acadêmicas presenciais da graduação, pós-graduação e educação ${ }^{1}$. Em comunicado da Reitoria, foi estabelecida a necessidade de migração de todas as atividades acadêmicas e administrativas para o contexto digital, o que significou a introdução do ensino remoto para toda a Universidade. A suspensão das atividades presenciais foi baseada a partir do decreto das Portarias No 343, de 17 de março de $2020^{2}$ e No 544 , de 16 de junho de $2020^{3}$ e da Medida Provisória No 934, de $1^{\circ}$ de abril de $2020^{4}$, que preveem a substituição, ou seja, a continuidade das aulas, antes presenciais, 
pelo ensino com uso de tecnologias digitais de informação e comunicação, com previsão até dezembro de 2020.

Para enfrentar este momento e recolocar a universidade em funcionamento, a Reitoria da Universidade tomou diversas ações destinadas a capacitar os docentes para o uso das diferentes ferramentas para comunicação com os estudantes, promover adequação do Departamento de Tecnologia de Informação, para dar suporte à nova demanda de dados que seriam utilizados, adequação dos serviços administrativos à nova situação e, por fim, dar apoio aos estudantes com restrições financeiras para que pudessem acompanhar as atividades.

\section{A capacitação do corpo docente para a transição para o ensino remoto}

Um dos grandes facilitadores para a transição para o ensino remoto na PUC-SP foi sua infraestrutura instalada de softwares, além de uma estrutura, mesmo que incipiente, de desenvolvimento docente. A Universidade já contava com a plataforma de ensino Moodle e o pacote Office $365 \AA$ da Microsoft ${ }^{\circledR}$, bem como acesso a bibliotecas virtuais. Apesar de dispor destas ferramentas tecnológicas, boa parte dos docentes tinha pouca expertise em seu uso de maneira geral e, menos ainda, em seu uso pedagógico. Uma explicação possível para a baixa literacia digital dos professores pode ser a faixa etária avançada do corpo docente, somada a uma práxis arraigada pelo tempo, característica de um corpo docente estável, com muito tempo de casa. Apesar de o censo da educação superior identificar que os docentes das universidades privadas têm idade aproximada de 38 anos, esta não é a realidade da PUC-SP5.

A Reitoria da Universidade designou uma equipe de apoio para realizar a transição de maneira efetiva e superar este momento, de modo que não houvesse comprometimento das atividades acadêmicas. A equipe multiprofissional foi composta de professores das diferentes áreas com expertise em tecnologias digitais de informação e comunicação, profissionais dos setores de tecnologia da informação e da biblioteca. Funcionários administrativos, principalmente aqueles que ajudavam de forma cotidiana os docentes, como os monitores dos laboratórios de informática, passaram a compor o suporte por e-mail ou telefone.

Em um primeiro momento, buscou-se a transposição rápida do ensino presencial para o ensino remoto por meio da capacitação tecnológica dos docentes para o uso das diferentes plataformas de ensino, com enfoque principalmente no uso da plataforma Microsoft Teams ${ }^{\circledR}$, que permite a transmissão síncrona e o compartilhamento de apresentações e, portanto, favorece a interação entre os participantes. O grupo responsável pela migração para o ensino remoto estabeleceu como primeiro objetivo a capacitação dos docentes para acesso às plataformas, inclusão dos estudantes nas salas, uso de recursos de comunicação e pedagógicos básicos, principalmente o compartilhamento de tela. É importante destacar que, no momento inicial, boa parte dos docentes, apesar de aderir às plataformas digitais, passou a simplesmente "repetir" suas práticas do ensino presencial no ensino remoto emergencial. A literatura também mostra que este espelhamento instrumental das atividades presenciais para o ensino remoto individual aconteceu em grande parte das instituições de ensino ${ }^{6,7}$. Cabe ressaltar que, com o movimento realizado inicialmente, tinha-se o objetivo de assegurar a retomada das aulas para os estudantes, contudo já havia a convicção de que ações voltadas a qualificar a atuação docente no novo momento eram prementes.

Sabe-se que o aprendizado e o uso pedagógico de recursos tecnológicos, agora potencializado pela adoção do ensino remoto, aliado à adoção de novas estratégias pedagógicas, são compreendidos como um processo de inovação da prática docente. Assim, modelos teóricos, como a teoria de Rogers ${ }^{8}$, podem ser implantados. Neste modelo, o processo de difusão de inovações ocorre ao longo do tempo e pode ser estruturado em cinco etapas específicas: conhecimento, convencimento, decisão, implementação e confirmação. Assim, a exposição dos professores ao ensino remoto cumpriu a etapa de conhecimento e exposição dos docentes às novas tecnologias, porém segundo Rogers, a exposição só favorece a inovação se for percebida como uma experiência relevante para satisfação das necessidades indivi- 
duais dos docentes, além de ser consistente com as atitudes e crenças dos indivíduos. O estágio de convencimento ocorre quando um indivíduo forma uma atitude pessoal positiva em relação à inovação. A fase de convencimento é influenciada por seus pares docentes, principalmente aqueles cuja opinião parece mais convincente ${ }^{8}$.

A adesão do corpo docente às oficinas básicas para o uso da Microsoft Teams ${ }^{\circledR}$ foi de aproximadamente $70 \%$ e a da plataforma Moodle foi de $40 \%$. Nas semanas seguintes, momentos pontuais de plantões de dúvidas para o uso das plataformas também foram criados. Outro aspecto relevante a ser destacado foi a necessidade de capacitação individualizada ou em pequenos grupos realizada junto ao grupo de professores com pouca habilidade no uso de computadores. Também se buscou a criação de espaço de fácil acesso, dentro do site da Universidade, que funcionasse como um repositório de materiais e dos treinamentos gravados para que o professor consultasse posteriormente. Segundo Oliveira, Correa e Morés (2020), uma boa prática no ensino remoto emergencial é ofertar espaços digitais para a interação entre docentes e compartilhamento de conteúdo de aulas entres docentes, o que representaria a diminuição da sobrecarga de trabalho e, mais ainda, favoreceria a troca de experiências e apoio mútuo em momento de incertezas e desafios, o que nos levou a acreditar que este espaço poderia ser o embrião de uma comunidade virtual de aprendizagem? ${ }^{\text {. }}$

Assim, no intervalo de uma semana a dez dias, a quase totalidade das atividades acadêmicas estavam retomadas e a maioria dos professores estavam aptos a criar uma equipe na $\mathrm{Mi}$ crosoft Teams ${ }^{\circledR}$, incluir seus estudantes, iniciar uma aula síncrona, compartilhando sua tela e, quando desejavam, gravar a atividade realizada ou ainda desenvolver atividades assíncronas na plataforma Moodle. As eventuais dúvidas eram resolvidas por plantões dos docentes envolvidos na capacitação docente.

Apesar da dificuldade imposta pelo momento, vislumbrou-se a necessidade de qualificar as práticas docentes em ambientes digitais e a possibilidade de aumentar o letramento digital dos docentes, de modo que, quando houvesse retorno às atividades presenciais eles incorporassem a cultura de uso das ferramentas digitais. Assim, havia a necessidade de que os docentes utilizassem em suas aulas remotas estratégias que promovessem a formação crítica, reflexiva e autônoma dos estudantes. Era importante que os docentes diminuíssem o tempo de transmissão em prol de um aprendizado mais participativo, com uso de metodologias inovadoras de ensino e aprendizagem ${ }^{10}$.

Assim, no primeiro semestre de 2020, foram realizadas oficinas docentes explorando estratégias pedagógicas diversificadas, conforme segue:

- Do Presencial ao Virtual: cujo objetivo foi mostrar aos docentes as particularidades do trabalho no ambiente virtual, ressaltando as diferenças entre ensinar em contextos presenciais, com práticas "convencionais", e ensinar em ambientes virtuais, em uma perspectiva interativa. Por exemplo, tratou-se da necessidade de se diminuir o tempo de exposição e aumentar o tempo dedicado ao "trabalho", compreendido como participação e realização de atividades por parte dos estudantes. Foram igualmente abordadas possibilidades de uso de ferramentas para avaliação no ensino remoto.

- Avaliação Remota: cujo objetivo foi abordar a avaliação formativa e a construção de rubricas formativas e promoveu uma relação entre elementos da Taxonomia de Bloom com ferramentas digitais que poderiam ser utilizadas na avaliação formativa.

- Estratégias Pedagógicas: foram ministradas oficinas que tiveram como objetivo a instrumentalização das ferramentas digitais, como o uso de quadros brancos, uso de murais, uso de mapas mentais e conceituais.

- Bibliotecas Digitais: a equipe da biblioteca apresentou aos docentes como se dá o acesso e uso das bibliotecas virtuais da universidade, integração dos livros eletrônicos ao Microsoft Teams ${ }^{\circledR}$, além do acesso a bases de dados externos, nacionais 
e internacionais e ao Portal de Periódicos CAPES - da Coordenação de Aperfeiçoamento de Pessoal de Nível Superior, entre outros.

Outras ações importantes adotadas pelo grupo gestor da Universidade foram a criação de uma equipe centralizada de comunicação institucional, intensificada e mais fluida, além de um canal de atendimento à saúde mental da comunidade puquiana, sob a responsabilidade de docentes do curso de Psicologia.

Cabe também destacar a preocupação da Reitoria e da Fundação São Paulo em relação a um provável aprofundamento da exclusão social e digital dos estudantes de menor renda: para estes estudantes foi custeado o aluguel de computadores e a oferta de chips de telefonia para acesso à interne, além de cestas básicas.

Desta forma, apesar de todas as dificuldades, as atividades do primeiro semestre se encerraram dentro do calendário institucional proposto, com boa avaliação de todos em relação à qualidade acadêmica ${ }^{1}$.

Com o aprendizado obtido no primeiro semestre, as atividades do segundo semestre se iniciam com um ganho importante: a expansão do grupo de docentes para apoio das atividades remotas. A ideia naquele momento é que tivéssemos representados no grupo de apoio docentes, um docente de cada faculdade e mais um dos cursos de pós-graduação, que desenvolvem atividades utilizando metodologias ativas de ensino aprendizagem e que servissem de exemplo para os demais docentes da Universidade. A intencionalidade neste momento, não era mais a promoção de oficinas, mas sim, promover um trabalho individualizado para o desenvolvimento docente, oportunidades de feedback e reflexão e elaboração de projetos ${ }^{11}$.Neste segundo momento, a intencionalidade já não era mais a oferta de oficinas de capacitação básica, mas sim a promoção de um trabalho individualizado para o

\footnotetext{
A Comissão Própria de Avaliação adaptou o instrumento de avaliação da docência com o objetivo de construir um diagnóstico relativo à docência no contexto remoto, totalmente atípico para a Universidade. Os dados revelaram bons índices de satisfação em relação ao trabalho realizado, tanto por parte dos docentes, quanto dos discentes.
}

desenvolvimento docente, criando oportunidades de diálogo, feedback e reflexão e elaboração de projetos $^{11}$, na perspectiva de uma formação contextualizada, em que a articulação entre teoria e prática seja essencial e que tenha a reflexão como eixo sustentador tanto da formação quanto da prática profissional12.13.14. Nessa linha, buscase contemplar o desenvolver planejamento, a execução, a análise, a reflexão e a correção de rumos e estratégias, configurando o ciclo de descrição-execução-reflexão-depuração ${ }^{15} 2$.

Simultaneamente a criação deste grupo de docentes, chamado de Grupo de Apoio às Atividades Remotas (GAAR), as pró-reitorias de Graduação e Pós-Graduação lançam um edital de seleção de discentes de pós-graduação da Universidade para apoio às atividades docentes e discentes no ambiente remoto. Foram selecionados 20 pós-graduandos, dos diversos programas da Universidade, que passaram a receber uma bolsa de estudos, sendo que destes 14 estudantes passaram a atender os docentes e mais seis responsáveis pelo atendimento a discentes (Figura 1). Um sistema informatizado de agendamento foi criado, de modo que o docente ou estudante da Universidade, marcava uma hora de atendimento individualizado com o estudante. Destaca-se que os atendimentos não eram para dúvidas técnicas, que eram superadas pelo suporte técnico, mas sim com a intenção de promover uma melhor utilização das plataformas associadas a metodologias inovadoras de ensino e aprendizagem.

\footnotetext{
Os autores e obras citados abordam o importante papel atribuído à reflexão na formação docente, seja para adoção de tecnologias digitais de informação e comunicação (TDIC), seja para atuação on-line, híbrida e/ou totalmente a distância, seja apenas para aprimoramento da prática, na perspectiva da formação continuada que, atualmente, inclui necessariamente o uso de TDIC em alguma medida. A despeito das particularidades de cada uma dessas abordagens e do fato de não estarmos tratando aqui de formação docente, de modo específico, mas sim de processos de mudança de uma cultura institucional cristalizada, que inclui a capacitação docente, a importância da reflexão se aplica, pois trata-se de processos de aprimoramento da prática profissional, de forma ampla (inclusive no segmento educacional). Destacam-se, igualmente, inúmeros estudos dedicados à defesa da necessária articulação entre teoria e prática, na área educacional, quer na formação docente, quer na formação profissional de forma mais ampla
} 


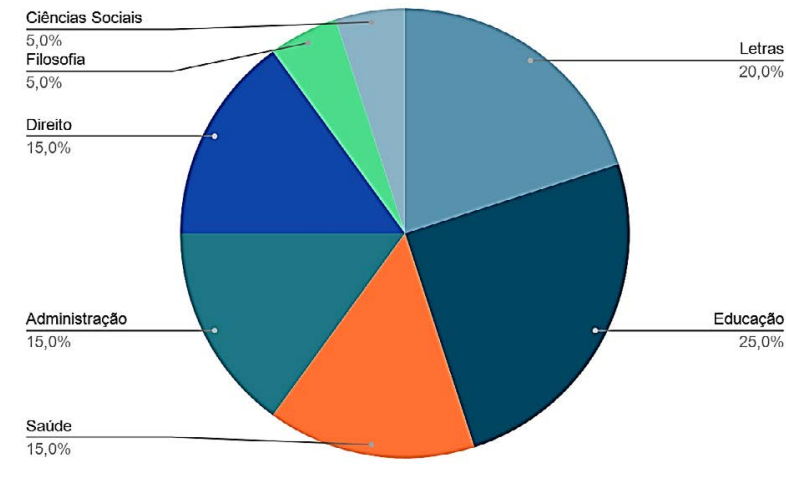

Figura 1: Programa de origem dos monitores do Grupo de Apoio às Atividades Remotas. Pontifícia Universidade Católica de São Paulo, março, 2021

A monitoria do GAAR era uma oportunidade para o estudante desenvolver habilidades de docência, aprofundar conhecimentos nas tecnologias educacionais e contribuir com o processo de ensino-aprendizagem dos docentes e estudantes ${ }^{16}$. Quando surgiam dúvidas, os estudantes tinham acesso direto aos docentes do GAAR, que os orientavam.

Ao final do semestre os estudantes do GAAR realizaram aproximadamente 150 atendimentos individuais de docentes e estudantes (considerando o período de agosto a dezembro de 2020), demandados principalmente por docentes e estudantes da graduação ( $51 \%)$, pós-graduação stricto-sensu (33\%) e lato-sensu (16\%). Os docentes foram os que mais solicitaram apoio do grupo, seguido de estudantes (Figura 2 ).

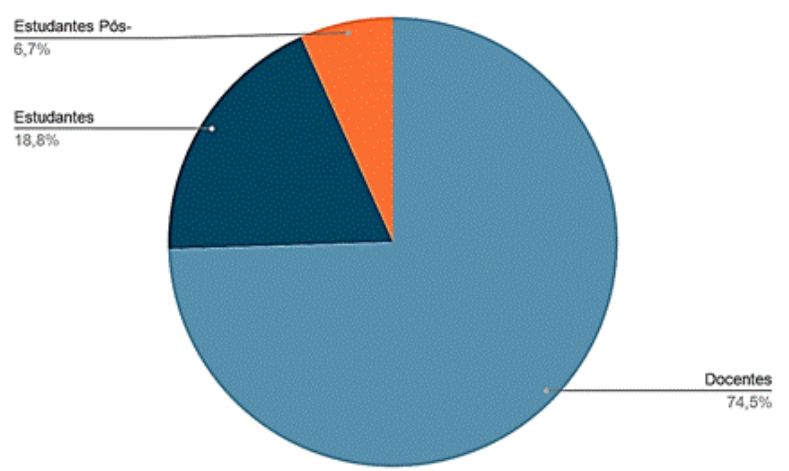

Figura 2: Público atendido pelos bolsistas do Grupo de Apoio às Atividades Remotas. Pontifícia Universidade Católica de São Paulo, março, 2021.
Por fim, é importante destacar que recentemente a instituição criou um Centro de Aperfeiçoamento Docente, que prevê ações perenes de desenvolvimento docente.

\section{O ENSINO REMOTO NA FACULDADE DE CIÊNCIAS MÉDICAS E DA SAÚDE (FCMS)}

A Faculdade de Ciências Médicas e da Saúde (FCMS), localiza-se em um campus na cidade de Sorocaba, distante aproximadamente 90 quilômetros da capital, e lá se encontram os cursos de Medicina e Enfermagem, bem como os programas de Residência Médica. Cabe destacar uma particularidade deste campus, uma vez que desde 2006, iniciando-se pelo curso de Medicina, houve a mudança dos currículos para abordagens que utilizam metodologias ativas de ensino-aprendizagem. Atualmente, o currículo do curso de medicina, em seus primeiros anos, tem atividades semanais na forma de aprendizagem baseada em problemas, atividades aplicadas junto às diferentes áreas de conhecimento, práticas junto aos pacientes no módulo de habilidades médicas, além da prática em atenção à saúde, que é desenvolvida junto à comunidade. Nesses primeiros três anos, para quase a totalidade das atividades os estudantes estão divididos em grupos de 10 ou 25 estudantes. $O$ único momento em que o curso pode se assemelhar ao modelo de aulas expositivas é uma atividade denominada sustentação teórica que tem carga semanal de apenas uma hora e conta com todos os estudantes da série, para uma aula teórica.

Desde 2014, o curso de Medicina inovou e o internato que outrora se estendia por dois anos passou a ter três anos de duração correspondendo, portanto, a cinquenta por cento do curso. As atividades do internato, conforme as Diretrizes Curriculares Nacionais para o Curso de Medicina devem ser atividades eminentemente práticas ${ }^{17}$.

À semelhança dos demais cursos da Universidade, as atividades na FCMS conseguiram rapidamente se organizar para garantir a continuidade do curso de forma remota. Parte das atividades foram retomadas em uma semana após o pronunciamento da reitoria da PUC-SP sobre o 
cancelamento das atividades presenciais. Após o esforço inicial dos gestores, professores e suporte técnico da Universidade de se estabelecer o contato remoto, introduzindo o uso da Microsoft Teams $^{\circledR}$, esta plataforma ainda não estava sendo utilizada pelos docentes do curso e era totalmente desconhecida para maioria dos docentes e discentes. O fato de o curso adotar, desde 2006 a plataforma Moodle como repositório e "quadro de avisos" do curso, pode ter sido uma vantagem, que pode ter favorecido à migração das atividades para o contexto remoto.

Assim, acredita-se que a adversidade para o curso de Medicina foi ainda maior que os demais cursos da Universidade. Além de adaptar um curso para o ensino remoto, o desafio maior, se não o mais difícil, era de como adaptar o currículo dos cursos que empregam de forma maciça as metodologias ativas de ensino e aprendizagem. Mais ainda, o curso de Medicina detém em sua grade horária uma significativa parcela de atividades práticas (laboratórios, internato e estágios profissionais) e essas tiveram de ser adiadas para reposição com o retorno das atividades presenciais.

Para os docentes das séries iniciais do curso ( $1^{\circ}$ ao $3^{\circ}$ ano), após a capacitação dos docentes para $\circ$ uso da plataforma Microsoft Teams ${ }^{\circledR}$, as atividades de tutoria, que se utiliza da estratégia pedagógica da aprendizagem baseada em problemas, as atividades teóricas, assim como as atividades de mentoria e algumas das aulas práticas migraram para o ambiente remoto. As atividades que envolviam a prática médica, que ocorrem desde o primeiro ano do curso, também migraram para o ensino remoto como aulas preparatórias para prática ("teoria para prática"), porém a complementação destes conteúdos teve de ser planejada para fases do Plano São Paulo que permitissem a ida dos estudantes as enfermarias e Unidades Básicas de Saúde. As avaliações formativas foram adaptadas para o uso de tarefas e participação em atividades propostas.

Se, de um lado a introdução do ensino remoto envolveu algumas perdas no processo de ensino e aprendizagem, de outro lado também trouxe ganhos aos docentes e aos cursos da FCMS, tais como o aumento de sua competência digital e a qualificação do processo de avaliação, principalmente da avaliação somativa.
A preocupação com a realização da avaliação somativa à distância decorria da premissa segundo a qual os estudantes teriam livre acesso às informações, que poderiam ser copiadas de sites e artigos. Assim, este "entrave" suscitou o aumento da dedicação e motivação dos professores para a elaboração de um novo modelo de avaliação somativa, evitando-se perguntas que levariam a respostas diretas, privilegiando-se alguma pesquisa e reflexão, para elaboração de respostas mais consistentes. Uma as consequências foi a intensificação do trabalho da Comissão de Avaliação, que passou a ter a participação das coordenadoras do curso, dos coordenadores dos eixos, dos módulos, além de docentes das diferentes áreas do saber, todos contribuindo para promover um avanço na qualidade da avaliação

Houve um incentivo ainda maior para que as questões das avaliações somativas valorizassem mais o raciocínio clínico e a interdisciplinaridade, em detrimento as questões que exigiam memorização, de forma a alinhar-se ainda mais aos pressupostos do Projeto Pedagógico do Curso de Medicina. O contexto de reuniões remotas facilitou a colaboração dos docentes, o que contribuiu para a qualificação das avaliações.

\section{O INTERNATO}

O curso de Medicina da PUC-SP oferece, desde 2019, o internato já a partir do $4^{\circ}$ ano. O internato implica em autêntica imersão nas atividades práticas de uma área específica, incluem plantões naquelas áreas em que são pertinentes e impõe $100 \%$ de presença. As turmas de cada um dos três anos do internato se subdividem para rodiziar ao longo do ano nas cinco grandes áreas da medicina: Tocoginecologia, Pediatria, Clínica Médica, Clínica Cirúrgica e Saúde Coletiva; portanto serão cerca de 20 estudantes por estágio. As práticas oferecidas obedecem a lógica da complexidade progressiva e das subáreas de cada uma dessas grandes áreas no $4^{\circ}, 5^{\circ}$ e $6^{\circ}$ anos.

As atividades práticas acontecem nos cenários da rede de atendimento ao Sistema único de Saúde de Sorocaba e Votorantim e, em alguns momentos também, em ambiente de atenção privada à saúde. 
A partir do crescente impacto da pandemia COVID-19, houve necessidade de se adequar todos os equipamentos de saúde para o atendimento da população, essas medidas suspenderam os atendimentos de rotina, que se constituem na grande fonte de ensino nas Unidades Básicas de Saúde para nossos internos, bem como suspenderam-se as cirurgias e procedimentos eletivos.

Paralelamente a essas medidas operacionais para otimizar os serviços de saúde no enfrentamento dos pacientes suspeitos ou acometidos pelo coronavírus, a Secretaria Municipal de Saúde de Sorocaba suspendeu os estágios de ensino em todos os serviços próprios e terceirizados até segunda ordem.

Essa medida foi um dos motivos que induziram a suspensão das atividades do Curso de Medicina e de Enfermagem, pois não seria mais possível levar os estudantes para as práticas de campo, atividade fundamental no internato.

As atividades desenvolvidas nos plantões dos hospitais foram mantidas, pois representava envolver pequenos números de estudantes em setores específicos, como a Unidade de Emergência, UTI e Centro Obstétrico e poderia atenuar as perdas de horas desenvolvidas pelos internos.

As dificuldades anteriormente explicitadas são externas à Universidade e se apresentaram a todos os cursos e estudantes do país e do exterior causadas, como se sabe, por uma situação de calamidade pública. De qualquer modo, dentro de nossos limites de atuação, pudemos adotar medidas para minimizar seus impactos negativos na formação de nossos estudantes, conforme apresentaremos a seguir.

\section{MEDIDAS PARA PERMITIR A RETOMA- DA DAS ATIVIDADES PRESENCIAIS}

É óbvio que ademais a todas as mudanças dos cenários práticos, professores, estudantes e seus pais estavam muito preocupados e receosos sobre a possibilidade de contágio pelo coronavírus. Tendo em vista as muitas necessidades que se precipitaram a partir deste momento de exceção, a gestão da FCMS estabeleceu algumas medidas em comum acordo com a Pró-Reitoria de Graduação e a Reitoria da Universidade.

Nessa direção, a gestão do curso convocou os professores de Saúde Coletiva (Prof. José Manoel Guerrero) e de Infectologia (Prof. Marcos Vinicius da Silva) para compor comitê de consultoria sobre as necessidades especiais no atendimento de pacientes contaminados pelo coronavírus nas diferentes situações clínicas.

Igualmente a gestão da universidade buscou organizar esforços no sentido de restabelecer as práticas de ensino em seus diferentes cursos, determinando que os técnicos das áreas de informática, os professores das áreas de educação com expertise nas práticas remotas, os setores da biblioteca e de audiovisual fossem disponibilizados para capacitação dos docentes nas plataformas e no uso correto de equipamentos eletrônicos no ensino, bem como dos funcionários, no apoio administrativo necessário à realização do conjunto de atividades acadêmicas

Sob o comando da Reitoria da PUC-SP, foi realizado um levantamento dos estudantes que não dispunham de condições materiais de acompanhar as aulas remotamente ou por não terem equipamentos ou por não disporem de acesso à rede mundial de computadores, com possibilidade de receber dados móveis em tempo real. Uma vez o diagnóstico concluído, a universidade forneceu os equipamentos e pacotes de dados necessários ao grupo mais vulnerável, o que viabilizou, em certo sentido, a permanência dos estudantes nos cursos. Naturalmente, nesse grupo havia estudantes dos cursos de Medicina e Enfermagem.

Por orientação do Comitê Consultor local foram calculadas as necessidades de equipamentos de proteção individual, constituídos por máscaras cirúrgicas, máscaras $\mathrm{N}-95$, protetores faciais e aventais descartáveis para uso quando as práticas de campo fossem retomadas. Esse levantamento foi encaminhado para o Grupo de Retomada constituído pela Fundação São Paulo, mantenedora da universidade, responsável pela orientação, análise e atendimento às demandas, para aquisição e disponibilização aos docentes e estudantes, com as respectivas orientações de uso. 


\section{RETOMADA DAS ATIVIDADES DE FORMA REMOTA}

Decorrido apenas uma semana da suspensão das atividades já era possível reiniciar algumas das atividades que passaram a ser disponibilizadas através das plataformas Microsoft Teams ${ }^{\circledR}$ e a Moodle da Universidade. Inicialmente as atividades eram exclusivamente teóricas e a transição da prática presencial para prática remota de forma síncrona se fez de maneira bastante satisfatória. Claro que algumas distorções ocorreram, como professores que preferiam usar o Whatsapp ${ }^{\circledR}$ para práticas de ensino remoto. Verificamos igualmente uma corrente de solidariedade, em que alguns professores que tinham dificuldade em usar equipamentos de informática eram orientados e, por vezes, substituídos por seus colegas.

Nos seis anos do curso de Medicina e nos quatro anos do curso de Enfermagem, as atividades que eram exclusivamente teóricas estavam sendo disponibilizadas de forma remota com boa participação dos estudantes. Nos primeiros três anos do curso eram aulas teóricas, denominadas de Sustentações Teóricas, para as demais atividades em que habitualmente seriam desenvolvidas na forma prática, foram adaptadas para que os conceitos teóricos que devem acompanhar as atividades práticas fossem oferecidos naquele momento. Para o internato, as atividades de reuniões científicas, seminários e discussões de caso eram possíveis ser apresentadas no formato remoto.

Nessa ocasião o Ministério da Educação publicou a Portaria no 492 de 23/03/202018, que autorizou adaptações para as práticas de ensino nos cursos das áreas da saúde, incluindo a presença de estudantes estagiários sob supervisão nos cenários de prática. Igualmente, o Ministério da Saúde publicou o Programa "Brasil Conta Comigo" (Portaria no 580 de 27/03/2020) ${ }^{19}$ que estimulava os municípios a oferecer espaço de estágio para estudantes que pretendessem se juntar aos profissionais da rede, reconhecendo as horas dedicadas a estes estágios como parte do estágio curricular obrigatório.

A gestão da faculdade, diretor e coordenadores de cursos, considerou que seria importan- te incluir um professor consultor da área de psiquiatria para o Comitê Consultor, assim a Profa. Nicoli Abrão Fasanela, se juntou ao grupo para dar acolhimento a estudantes e professores cujas dificuldades em lidar com as novas situações decorrentes da pandemia tivessem sua saúde mental comprometida.

Como a FCMS também tem os programas de Residência Médica, as atividades de atendimento aos pacientes que não foram suspensas pela pandemia continuaram a acontecer normalmente, sem a presença dos internos, nas fases iniciais da pandemia. Diante da necessidade de assegurar a qualidade da formação dos estudantes também na dimensão prática e considerando o fato de a universidade ter adquirido os equipamentos de proteção individual necessários, iniciaram-se os estudos para reintroduzir os internos nas práticas de campo.

Ao longo de todo o mês de abril houve reuniões entre a gestão do curso e os responsáveis pelos estágios para organizar a retomada, de modo que a partir do dia 11 de maio de 2020 foi possível receber os internos dos três anos do curso de Medicina.

Após um semestre de realização das atividades previstas pelo projeto pedagógico de maneira remota, foi realizada uma pesquisa com os estudantes, graduandos em Medicina, do primeiro ao terceiro ano sobre as estratégias utilizadas e as dificuldades enfrentadas. A partir dela, foi possível verificar o reconhecimento do esforço de todos os envolvidos no processo, a aprovação na maneira de compartilhamento do conteúdo teórico previsto, além das dificuldades em relação às atividades práticas, confirmando a necessidade de se buscar soluções para que os alunos pudessem completar as horas presenciais previstas, nos diversos campos de estágio. Um dos resultados importantes desta pesquisa foi a opinião dos estudantes sobre o uso da aprendizagem baseada em problemas ( $A B P$ ) em modo remoto, até então, uma experiência inédita na FCMS. Os resultados, na opinião de estudantes do segundo e o terceiro ( $85 \%$ dos estudantes) evidenciam a aprovação do uso da $A B P$, conforme a Figura 3. 


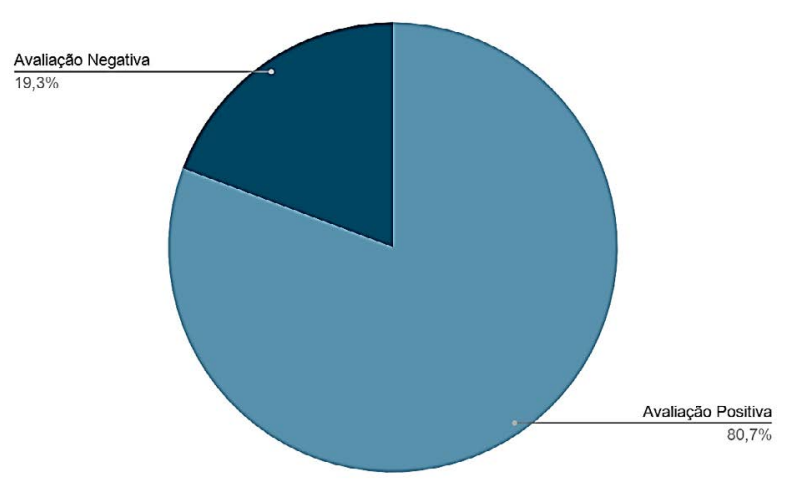

Figura 3: Avaliação das tutorias no período remoto na Aprendizagem Baseada em Problema. Opinião de 254 estudantes do curso de Medicina da Faculdade de Ciências Médicas da PUC, SP. Dezembro, 2020

Também foi possível ter a palavra dos participantes do processo sobre o quanto o isolamento social e os fatores relacionados com a pandemia trouxeram prejuízo para saúde mental nos mais diversos aspectos.

\section{CONCLUSÕES}

Na PUC-SP, apesar das dificuldades iniciais enfrentadas pelo corpo docente, o grupo envolvido com as ações de capacitação docente, conseguiu restabelecer rapidamente as atividades de forma remota na Universidade. Além das oficinas para um grande grupo de professores, foi necessário, por muitas vezes, trabalhar em pequenos grupos, ou ainda de forma individualizada, com professores com menor letramento digital. $\mathrm{O}$ olhar atento às necessidades dos estudantes foi uma preocupação importante que foi resolvida por ação conjunta da reitoria e da mantenedora.

Outro ponto importante a ser destacado é que a experiência de capacitação intensiva durante a pandemia contribuiu para desencadear as ações iniciais do recém-criado Centro de Aperfeiçoamento Docente. A seleção de estudantes pósgraduandos monitores para apoio às atividades remotas favoreceu o atendimento individualizado da comunidade acadêmica. Também qualificou os monitores para o exercício da docência. Por fim, o curso de Medicina, adequou-se de maneira eficiente às atividades remotas. A necessidade de atuar de forma remota promoveu uma maior colaboração entre os docentes.

\section{BIBLIOGRAFIA}

1. Pontifícia Universidade Católica de São Paulo. COVID-19: Comunicado da PUC-SP 16/03/2020 - 17h [Internet]. Jornal PUC-SP. [citado 9 de março de 2021]. Disponível em: https://j.pucsp.br/noticia/covid-19-comunicadoda-puc-sp-16032020-17h

2. BRASIL. PORTARIA No 343, DE 17 DE MARÇO DE 2020 - DOU - Imprensa Nacional [Internet]. [citado 11 de março de 2021]. Disponível em: https://www.in.gov.br/ web/dou

3. BRASIL. PORTARIA No 544, DE 16 DE JUNHO DE 2020 - DOU - Imprensa Nacional [Internet]. [citado 11 de março de 2021]. Disponível em: https://www.in.gov.br/ web/dou

4. BRASIL. MEDIDA PROVISÓRIA № 934, DE $1^{\circ}$ DE ABRIL DE 2020 - DOU - Imprensa Nacional [Internet]. [citado 11 de março de 2021]. Disponível em: https://www.in. gov.br/web/dou

5. Instituto Nacional de Estudos e Pesquisas Educacionais Anísio Teixeira (Inep). Censo da Educação Superior 2018 [Internet]. 2019. Disponível em: https://download.inep. gov.br/educacao superior/censo superior/documentos/2019/censo_da_educacao_superior_2018-notas estatisticas.pdf

6. Moreira JAM, Henriques S, Barros D. Transitando de um ensino remoto emergencial para uma educação digital em rede, em tempos de pandemia. Dialogia. 3 de junho de 2020;0(34):351-64.

7. Smith E, Boscak A. A virtual emergency: learning lessons from remote medical student education during the COVID-19 pandemic. Emerg Radiol [Internet]. 8 de janeiro de 2021 [citado 11 de março de 2021]; Disponível em: https://doi.org/10.1007/s10140-020-01874-2

8. MOSELEY SF. Everett Rogers' Diffusion of Innovations Theory: Its Utility and Value in Public Health. J Health Commun. $1^{\circ}$ de janeiro de 2004;9(sup1):149-51.

9. Oliveira RM de, Corrêa Y, Morés A. Ensino remoto emergencial em tempos de covid-19: formação docente e tecnologias digitais. Rev Int Form Profr. 14 de setembro de 2020;5:e020028-e020028.

10. Goodman BE, Barker MK, Cooke JE. Best practices in active and student-centered learning in physiology classes. Adv Physiol Educ. $1^{\circ}$ de setembro de 2018;42(3):417-23.

11. Steinert $Y$, Mann K, Anderson B, Barnett BM, Centeno A, Naismith $L$, et al. A systematic review of faculty development initiatives designed to enhance teaching effectiveness: A 10-year update: BEME Guide No. 40. Med Teach. 2 de agosto de 2016;38(8):769-86.

12. Manen M van. On the Epistemology of Reflective Practice. Teach Teach. $1^{\circ}$ de março de $1995 ; 1(1): 33-50$. 
13. Valente J. Formação de profissionais na área de informática em educação. Computadores e Conhecimento: Repensando a Educação. 1 ed 1993;114-34.

14. Geraldini A. Docência no ambiente digital: ações e reflexão [Doutorado]. Pontifícia Universidade Católica de São Paulo; 2003.

15. Prado MEBB. Educação a distância na e para a formação reflexiva do professor. ETD - Educ Temática Digit. 7 de outubro de 2009;10(2):203-22.

16. Natário EG, Santos AAA dos. Programa de monitores para o ensino superior. Estud Psicol Camp. setembro de 2010;27(3):355-64.
17. BRASIL. Diretrizes Curriculares Nacionais do Curso de Medicina. 2014; Disponível em: http://portal.mec.gov. br/index.php?option=com docman\&view=download\&alias $=15874-$ rces003-14\&category slug=junho-2014-pdf\&Itemid $=30192$

18. BRASIL. PORTARIA No 492, DE 23 DE MARÇO DE 2020 - DOU - Imprensa Nacional [Internet]. [citado 11 de março de 2021]. Disponível em: https://www.in.gov.br/ web/dou

19. BRASIL. PORTARIA No 580, DE 27 DE MARÇO DE 2020 - DOU - Imprensa Nacional [Internet]. [citado 11 de março de 2021]. Disponível em: https://www.in.gov.br/ web/dou

Editor:

Prof. Dr. Marcelo Riberto

Recebido: $30 / 04 / 2021$

Aprovado: 13/07/2021

(c) (i) Este é um artigo publicado em acesso aberto (Open Access) sob a licença Creative 